\title{
Ocular effects of exposure to triethylamine in the sand core cold box of a foundry
}

Mary Jo Reilly, Kenneth D Rosenman, John H Abrams, Zhiwei Zhu, Chih-yu Tseng, Vicki Hertzberg, Carol Rice

\begin{abstract}
Objectives-To assess the acute and chronic ophthalmological effects of triethylamine exposure among foundry workers. Methods-Ocular effects on people currently, previously, and never exposed to triethylamine in a foundry cold box were studied at two points in time. The initial phase included an ocular examination with a slit lamp to assess corneal health, a visual acuity test, and a questionnaire to assess vision symptoms. The follow up included measurements of corneal thickness with an ultrasonic pachymeter and the vision symptoms questionnaire before and after the shift and at the beginning and end of the week. Personal air measurements for triethylamine were also obtained during the follow up.

explanations for these symptoms without corneal oedema are that triethylamine affects ciliary muscle function or that the corneal oedema was transient and not present when corneal thickness measurements were taken. No chronic effects were found in previously exposed workers. Further research is needed to elucidate the mechanism for the reported vision symptoms, which occurred below the current United States eight hour time weighted standard of $100 \mathrm{mg} / \mathrm{m}^{3}$ and the American Conference of Governmental Industrial Hygienists (ACGIH) recommended value at the time of our study of $40 \mathrm{mg} / \mathrm{m}^{3}$. We recommend that air concentrations be maintained to meet the current recommended ACGIH threshold of $4 \cdot 1 \mathrm{mg} / \mathrm{m}^{3}$.
\end{abstract}

Results-The vision symptoms of blurriness, halos around lights, and blue hazy vision occurred more often in currently exposed workers than those previously or never exposed to triethylamine. Air concentrations of triethylamine ranged from $<0.33 \mathrm{mg} / \mathrm{m}^{3}$ to $20.3 \mathrm{mg} / \mathrm{m}^{3}$. Among currently exposed workers, symptoms were more common among those with exposure to $>10 \mathrm{mg} / \mathrm{m}^{3}$ of triethylamine (odds ratio $(O R)=3.0,95 \%$ confidence interval $(95 \% \mathrm{CI}) \quad 0 \cdot 35-25 \cdot 6)$. No differences in corneal thickness were found in currently or previously exposed workers and those never exposed. No increase in corneal thickness was found after $v$ before the shift.

Conclusion-Despite low concentrations of triethylamine and no corneal oedema, workers exposed to triethylamine reported vision symptoms. Possible
(Occup Environ Med 1995;52:337-343)

\section{Keywords: triethylamine; foundry; vision symptoms}

Tertiary amines have been used in foundries since the middle to late 1940 s and the hazards of exposures to these amines have been recognised in the scientific literature since their introduction. ${ }^{12}$ Occupational exposures to tertiary amines including triethylamine are recognised to cause vision symptoms of blurriness, halos around lights, and blue hazy vision. ${ }^{1-7}$ The vision symptoms are typically short term, lasting generally about an hour after the end of exposure, and are attributed to light scattering associated with corneal oedema. Corneal oedema occurs when the amine acts directly on the corneal epithelium. Albrecht and colleagues provide a

Fee Hall, East

Lansing, Michigan

M J Reilly

K D Rosenman

Z Zhu

Indianapolis, Indiana

J H Abrams

University of

Cincinnati,

Department of

Environmental

Health, Cincinnati,

Ohio

C Tseng

V Hertzberg

C Rice

Correspondence to:

Mary Jo Reilly, Michigan

State University, College of

Human Medicine,

Department of Medicine,

B-117 West Fee Hall, Eas

Lansing, Michigan 48824-

1316, USA.

Accepted 19 January 1995

Table 1 Vision symptoms * by exposure: initial and follow up eye examinations

\begin{tabular}{|c|c|c|c|c|c|c|c|}
\hline & \multirow{2}{*}{\multicolumn{3}{|c|}{ Initial examination }} & \multicolumn{4}{|c|}{ Follow up examination } \\
\hline & & & & \multirow{2}{*}{$\begin{array}{l}\text { Current } \\
\text { day } 1 \\
n(\%)\end{array}$} & \multirow{2}{*}{$\begin{array}{l}\text { Current } \\
\text { day } 2 \\
n(\%)\end{array}$} & \multirow[b]{2}{*}{$\begin{array}{l}\text { Previous } \\
n(\%)\end{array}$} & \multirow[b]{2}{*}{$\begin{array}{l}\text { Never } \\
n(\%)\end{array}$} \\
\hline & $\begin{array}{l}\text { Current } \\
n(\%)\end{array}$ & $\begin{array}{l}\text { Previous } \\
n(\%)\end{array}$ & $\begin{array}{l}\text { Never } \\
n(\%)\end{array}$ & & & & \\
\hline Blurry vision & $19(95 \cdot 0)$ & $\begin{array}{l}12(52 \cdot 2) \\
P<0 \cdot 0001\end{array}$ & $5(21 \cdot 7)$ & $\begin{array}{l}4(36.4) \S \\
P=0.0975\end{array}$ & $\begin{array}{l}6(54.5) S \\
P=0.0050\end{array}$ & $3(14 \cdot 3)$ & $1(5 \cdot 9)$ \\
\hline Halos & $18(90 \cdot 0)$ & $8(34.8)$ & $3(13 \cdot 0)$ & $2(18 \cdot 2) \S$ & $\begin{array}{l}6(54.5) \Omega \\
P<0.0001\end{array}$ & $0(0 \cdot 0)$ & $0(0 \cdot 0)$ \\
\hline Blue colour & $6(30 \cdot 0)$ & $2(8 \cdot 7) \S$ & $1(4 \cdot 3)$ & $4(36 \cdot 4) \S$ & $3(27 \cdot 3) \S$ & $0(0 \cdot 0)$ & $0(0.0) \dagger$ \\
\hline Trouble driving & $14(73 \cdot 7) \ddagger$ & $\begin{array}{l}7(30.4) \\
P<0.0001\end{array}$ & $2(8 \cdot 7)$ & $0(0 \cdot 0)$ & $0(0.0)$ & $0(0 \cdot 0)$ & $0(0 \cdot 0)$ \\
\hline
\end{tabular}

«The initial examination investigated symptoms without reference to time: the follow up eye examination investigated symptoms that day.

†One individual response missing.

fOne person does not drive.

Expected count in one or more cells is $<5$. 
Table 2 Ocular effects of exposure to triethylamine

\begin{tabular}{|c|c|c|c|c|c|c|c|c|c|c|}
\hline \multirow{3}{*}{ Subject No } & \multirow{3}{*}{$\begin{array}{l}\text { Exposure } \\
\left(\mathrm{mg} / \mathrm{m}^{3}\right)\end{array}$} & \multicolumn{6}{|c|}{ Subjective symptoms* } & \multirow{2}{*}{\multicolumn{3}{|c|}{ Before to after shift changes in corneal thicknesst }} \\
\hline & & \multirow{2}{*}{$\begin{array}{l}\text { Burning } \\
\text { eyes }\end{array}$} & \multirow{2}{*}{$\begin{array}{l}\text { Blurry } \\
\text { vision }\end{array}$} & \multirow{2}{*}{$\begin{array}{l}\text { Halo } \\
\text { vision }\end{array}$} & \multirow[b]{2}{*}{ Colour } & \multirow{2}{*}{$\begin{array}{l}\text { Smell of } \\
\text { triethylamine }\end{array}$} & \multirow{2}{*}{$\begin{array}{l}\text { Leak of } \\
\text { triethylamine }\end{array}$} & & & \\
\hline & & & & & & & & Right & Left & Average of both \\
\hline \multicolumn{11}{|c|}{ Day 1 of the follow up eye examinations } \\
\hline 1 & $5 \cdot 29$ & + & + & - & + & No data & No data & -0.001 & -0.001 & -0.001 \\
\hline 2 & 3.72 & - & - & - & - & + & - & +0.002 & +0.003 & +0.003 \\
\hline 3 & $2 \cdot 64$ & - & - & - & - & + & + & -0.019 & +0.001 & -0.009 \\
\hline 4 & $9 \cdot 83$ & + & - & - & - & No data & No data & -0.006 & +0.003 & -0.002 \\
\hline 5 & $7 \cdot 19$ & - & + & + & + & + & + & -0.002 & +0.001 & -0.001 \\
\hline 6 & $14 \cdot 54$ & - & - & - & + & + & + & -0.011 & -0.003 & -0.007 \\
\hline 7 & $<0.33$ & - & + & + & + & - & - & +0.006 & -0.020 & -0.007 \\
\hline 8 & No data & - & - & - & - & + & + & +0.004 & -0.002 & +0.001 \\
\hline 9 & $1 \cdot 57$ & - & - & - & - & + & - & +0.001 & -0.018 & -0.009 \\
\hline 10 & $9 \cdot 91$ & - & - & - & - & - & - & $\ddagger$ & $\ddagger$ & $\ddagger$ \\
\hline 11 & No data & + & + & - & - & + & + & $\ddagger$ & $\ddagger$ & $\ddagger$ \\
\hline \multicolumn{11}{|c|}{ Day 2 of the follow up eye examinations } \\
\hline 1 & $4 \cdot 5$ & + & + & + & - & + & - & -0.013 & -0.008 & -0.011 \\
\hline 2 & $6 \cdot 4$ & - & - & - & - & + & - & -0.009 & -0.012 & -0.011 \\
\hline 3 & $1 \cdot 7$ & - & - & + & - & + & + & +0.011 & +0.006 & +0.009 \\
\hline 4 & $5 \cdot 0$ & - & + & + & - & + & + & -0.010 & -0.011 & -0.011 \\
\hline 5 & $20 \cdot 3$ & - & + & + & - & + & + & -0.001 & -0.013 & -0.007 \\
\hline 6 & $14 \cdot 5$ & + & + & - & + & + & + & NC & -0.008 & -0.004 \\
\hline 7 & No data & + & + & + & + & + & - & +0.008 & -0.008 & NC \\
\hline 8 & $11 \cdot 1$ & - & + & + & + & + & + & +0.008 & +0.001 & +0.005 \\
\hline 9 & No data & - & - & - & - & + & + & +0.001 & NC & +0.001 \\
\hline 10 & $12 \cdot 0$ & - & - & - & - & + & + & +0.002 & -0.006 & -0.002 \\
\hline 11 & No data & + & - & - & - & + & + & +0.006 & NC & +0.003 \\
\hline
\end{tabular}

$\star+=$ yes; $-=$ no

$t+=$ increase $;-=$ decrease NC $=$ no change

‡Only one corneal measurement taken during day 1 ; no second measurement for comparison.

comprehensive summary of the anatomy, physiology, toxicology, and history of the vision effects of exposure to tertiary amines. ${ }^{1}$

Tertiary amines, including triethylamine, are used in foundries as catalysts in the formation of sand cores and moulds. ${ }^{8}$ When amines are used as the catalyst, the cores are produced in what is typically referred to as a cold box or isocure operation. Hydraulic presses pack sand in a pattern to form the core. The amine is pumped through a hose and pressure is applied to produce the core for a mould. The cold box operators who run the machines are exposed when excess sand builds up in the pattern, which allows the amine to escape from the seals around the cold box, and when there are breaks in the hoses that supply the amine to the core making machine. Cold box operators are also exposed to triethylamine as the core is removed from the core making machine while the core is still curing. ${ }^{78}$

The purpose of this study was to assess the association of ocular effects with triethylamine exposure at a foundry in Indiana, through physical examination of the corneas of cold box operators exposed to triethylamine and a vision symptoms questionnaire. We wanted to find out if cold box operators had corneal oedema as well as vision disturbances potentially associated with the corneal oedema, and to find out if there was evidence of long term corneal damage.

\section{Methods}

OUTLINE OF EYE EXAMINATIONS

An initial eye examination was conducted by two ophthalmologists and included an ocular examination with a biomicroscope (slit lamp)

Table 3 Comparison of mean (SD)* and mean (SD) change of the central corneal thickness of current cold box operators before and after a shift with previous and never exposed groups

\begin{tabular}{|c|c|c|c|c|c|c|}
\hline & \multicolumn{6}{|c|}{ Corneal thickness ( $\mathrm{mm}$ ) } \\
\hline & \multicolumn{2}{|l|}{ Day 1} & \multicolumn{2}{|l|}{ Mid-shift } & \multicolumn{2}{|l|}{ Day 2} \\
\hline & Right eye & Left eye & Right eye & Left eye & Right eye & Lefi eye \\
\hline \multicolumn{7}{|l|}{$\begin{array}{l}\text { Current: } \\
\text { Before shift: }\end{array}$} \\
\hline $\begin{array}{l}\text { Mean (SD) } \\
\text { Range } \\
\text { After shift: }\end{array}$ & $\begin{array}{l}0.512(0.033) \\
0.477-0.566\end{array}$ & $\begin{array}{l}0.519(0.024) \\
0.495-0.567\end{array}$ & - & - & $\begin{array}{l}0.511(0.024) \\
0.470-0.545\end{array}$ & $\begin{array}{l}0.525(0.027) \\
0.492-0.565\end{array}$ \\
\hline $\begin{array}{l}\text { Mean (SD) } \\
\text { Range } \\
\text { Previous: }\end{array}$ & $\begin{array}{l}0.513(0.025) \\
0.481-0.555\end{array}$ & $\begin{array}{l}0.520(0.026) \\
0.482-0.564\end{array}$ & - & - & $\begin{array}{l}0.511(0.026) \\
0.478-0.545\end{array}$ & $\begin{array}{l}0.519(0.029) \\
0.487-0.558\end{array}$ \\
\hline Mean (SD) & - & - & $0.511(0.031)$ & $0.516(0.029)$ & - & - \\
\hline $\begin{array}{l}\text { Range } \\
\text { Never: }\end{array}$ & - & - & $0.460-0.583$ & $0.464-0.581$ & - & - \\
\hline $\begin{array}{l}\text { Mean (SD) } \\
\text { Range }\end{array}$ & 二 & - & $\begin{array}{l}0.518(0.044) \\
0.456-0.620\end{array}$ & $0.517(0.036)$ & - & - \\
\hline Change over the shift: & & & $0.456-0.620$ & $0.461-0.605$ & - & 一 \\
\hline $\begin{array}{l}\text { Mean }(\mathrm{SD}) \\
\text { P value }\end{array}$ & $\begin{array}{l}10.003(0.003) \\
0.3071\end{array}$ & $\begin{array}{l}\stackrel{10.004}{ }+(0.003) \\
0.2080\end{array}$ & - & 二 & $\begin{array}{l}\uparrow<0.001(0.002) \\
0.9122\end{array}$ & $\begin{array}{l}\downarrow 0.005 \\
0.0165\end{array}$ \\
\hline
\end{tabular}

*There were no statistical differences between the values of current cold box operators before and after the shift and the values of $\uparrow=$ increase. never exposed groups. P values with the Wilcoxon rank sum scores ranged from $0.3315-0.9843$. $\downarrow=$ decrease; $=$ increase. 
Table 4 Current cold box operators: changes from beginning of week (day 1) to end of week (day 2) in central corneal thickness $(\mathrm{mm})$

\begin{tabular}{|c|c|c|c|}
\hline Comparison & Right eye & Left eye & $\begin{array}{l}\text { Right and left } \\
\text { eyes combined }\end{array}$ \\
\hline $\begin{array}{l}\text { Before shift day } 1 \text { to before shift day } 2 \text { : } \\
\text { Mean (SEM) } \\
\text { P value }\end{array}$ & $\begin{array}{l}\downarrow 0 \cdot 004(0 \cdot 004) \\
0 \cdot 2854\end{array}$ & $\begin{array}{l}\downarrow 0.001(0.003) \\
0.6152\end{array}$ & $\begin{array}{l}\downarrow 0 \cdot 003(0 \cdot 002) \\
0 \cdot 1476\end{array}$ \\
\hline $\begin{array}{l}\text { Before shift day } 1 \text { to after shift day } 2 \text { : } \\
\text { Mean (SEM) } \\
\text { P value }\end{array}$ & $\begin{array}{l}\downarrow 0.005(0.004) \\
0.2457\end{array}$ & $\begin{array}{l}\downarrow 0.006^{\star}(0.003) \\
0.0376\end{array}$ & $\begin{array}{l}\downarrow 0.005^{\star} \\
0.0225\end{array}$ \\
\hline $\begin{array}{l}\text { After shift day } 1 \text { to before shift day } 2 \text { : } \\
\text { Mean (SEM) } \\
\text { P value }\end{array}$ & $\begin{array}{l}\downarrow 0 \cdot 002(0.002) \\
0.4009\end{array}$ & $\begin{array}{l}\uparrow 0.004(0.003) \\
0.1889\end{array}$ & $\begin{array}{l}\uparrow 0.001(0.002) \\
0.5314\end{array}$ \\
\hline $\begin{array}{l}\text { After shift day } 1 \text { to after shift day } 2 \text { : } \\
\text { Mean (SEM) } \\
\text { P value }\end{array}$ & $\begin{array}{l}\downarrow 0.002(0.003) \\
0.5273\end{array}$ & $\begin{array}{l}\downarrow 0.001 \\
0.7597\end{array}$ & $\begin{array}{l}\downarrow 0.002 \\
0.5887\end{array}$ \\
\hline
\end{tabular}

to assess corneal health, a test of visual acuity, and a questionnaire to assess vision symptoms. The follow up eye examinations used a portable ultrasonic pachymeter to measure corneal thickness and a vision symptoms questionnaire to assess symptoms at the time of the pachymetry measurements. The second phase also included personal air sampling for triethylamine. The protocol was approved as part of a larger study protocol by Michigan State University's Committee on Research Involving Human Subjects.

\section{SELECTION OF STUDY PARTICIPANTS}

The currently exposed group was defined as cold box operators and their supervisors. To assess the possibility of chronic ophthalmological effects from triethylamine after exposure ended, one control group was composed of previously exposed people. A second control group was composed of people who had never worked as cold box operators. Controls were randomly selected from current employees who were not cold box operators. We attempted to select one control for each exposed subject.

To maximise the chance of finding a chronic effect, we identified all workers who had documentation from the medical department of a previous acute exposure to triethylamine during leaks; six workers were identified. One of the six was identified from the company's 1990 Occupational Safety and

Table 5 Comparison of mean central cormeal thickness of current cold box operators before and after the shift with previous and never exposed groups by number of symptoms reported

\begin{tabular}{|c|c|c|c|c|c|c|}
\hline \multirow[b]{4}{*}{ Symptoms } & \multicolumn{6}{|c|}{ Exposure group and time of measurement } \\
\hline & \multicolumn{4}{|c|}{ Current } & \multirow[b]{3}{*}{ Previous } & \multirow[b]{3}{*}{ Never } \\
\hline & \multicolumn{2}{|l|}{ Day 1} & \multicolumn{2}{|l|}{ Day 2} & & \\
\hline & Before & After & Before & After & & \\
\hline \multicolumn{7}{|l|}{ Right eye: } \\
\hline 0 & 0.506 & 0.508 & 0.520 & 0.522 & 0.514 & 0.520 \\
\hline \multicolumn{7}{|l|}{ Left eye: } \\
\hline 0 & 0.514 & 0.516 & 0.531 & 0.529 & 0.519 & 0.518 \\
\hline$\geqslant 1$ & 0.526 & 0.525 & 0.519 & 0.511 & 0.500 & 0.497 \\
\hline
\end{tabular}

Comparison of difference for all means showed $P$ values $>0.05$. The smallest $P$ values were 0.1977 (right eye) and 0.3417 (left eye), which were found in the comparison of currently exposed means after the shift in people with no symptoms with people with one or more symptoms.
Health Administration injury and illness records; the other five were identified from a $\log$ book kept by the company physician from 1984 to 1985.

Controls were matched to exposed subjects on age within three years, race, and sex, with nine exceptions. Two controls differed from the currently exposed group by more than three years of age; two differed by race; and five previously exposed workers differed by more than three years of age and by race.

\section{OPHTHALMOLOGICAL EXAMINATIONS}

The first eye examination clinic was held at the foundry medical department, with two ophthalmologists. The examination included a Snellen vision test for visual acuity, a slit lamp examination of the anterior segment of the eye, and a questionnaire to assess ocular symptoms without reference to time that included ever experiencing blurry vision, halo vision, blue vision, eye irritation, and a medical history of eye problems. The second eye examination clinic was also held at the foundry, in a room separated from but near the cold box production area. Measurements before and after the shift of corneal thickness of cold box operators were performed on a day at the beginning of the working week and on a day at the end of the working week. The previously and never exposed groups had one measurement of corneal thickness performed in the middle of the shift on one day during the course of the week. The corneal thickness was measured with a hand held ultrasonic pachymeter, the Pach Pen manufactured by Oculab (Glendale, CA). All measurements were taken in $\mathrm{mm}$ to one thousandth at the centre of the cornea.

One to two drops of the same anaesthetic were placed in each eye of both exposed and control subjects. These drops do not cause oedema and the pachymetry could not be performed without them. One ophthalmological technician took all the corneal thickness measurements. Three measurements were taken for each eye and the average of the three measurements was used for all analyses. Current vision symptoms were assessed when the pachymeter readings were taken.

\section{AIR MONITORING FOR TRIETHYLAMINE}

Personal air sampling for triethylamine was 
Table 6 Association of symptoms reported by current cold box operators by exposure to triethylamine

\begin{tabular}{|c|c|c|}
\hline \multirow[b]{2}{*}{$\begin{array}{l}\text { Exposure to } \\
\text { triethylamine }\end{array}$} & \multicolumn{2}{|c|}{ Number of symptoms } \\
\hline & $\begin{array}{l}\text { None } \\
n(\%)\end{array}$ & $\begin{array}{l}\geqslant 1 \\
n(\%)\end{array}$ \\
\hline $\begin{array}{l}<10 \mathrm{mg} / \mathrm{m}^{3} \\
\geqslant 10 \mathrm{mg} / \mathrm{m}^{3}\end{array}$ & $\begin{array}{l}6(50) \\
1(20)\end{array}$ & $\begin{array}{l}6(50) \\
4(80)\end{array}$ \\
\hline
\end{tabular}

with continuity correction: $O R=3 \cdot 0,95 \%$ CI $0 \cdot 35-25 \cdot 6$.

conducted throughout the week of the follow up examinations. Samples were collected on charcoal tubes and analysed by gas chromatography. On one day parallel sampling was performed with silica gel collection tubes. Also, cold box operators and their supervisors were questioned at the end of their shift about any leaks that day or being able to smell triethylamine during their shift.

\section{ANALYSES}

$\chi^{2}, t$ tests, general linear models (GLM) procedure, and the Wilcoxon rank sum scores procedure were used to make comparisons of differences and changes in eye thickness within and between shifts and days for the currently exposed group and between the currently exposed and control groups.

\section{Results}

For the initial examination, 74 workers were invited and 66 actually participated: 20 currently exposed, 23 previously exposed, and 23 never exposed. Two workers could not attend for unrelated medical reasons and another six chose not to participate. At the follow up examination, 51 of the original 66 workers participated: 11 currently exposed, 23 previously exposed, and 17 never exposed. The exposure of five currently exposed workers from the initial examination changed to previously exposed in the follow up examination. Two workers in the previously exposed group during the follow up examination were only included in the initial analyses as they filled in as cold box operators on the day of the follow up examination.

The currently, previously, and never exposed groups were similar in mean age $(38.6,43.3$, and 41.5 years), ethnic

Table 7 Comparison of mean central cormeal thicknes ( $\mathrm{mm}$ ) on either day for current cold box operators by exposure to triethylamine

\begin{tabular}{llll}
\hline & \multicolumn{2}{l}{$\begin{array}{l}\text { Concentration of exposure to } \\
\text { triethylamine }\end{array}$} & \\
\cline { 2 - 3 } & $\begin{array}{l}<10 \mathrm{mg} / \mathrm{m}^{3} \\
\text { Mean (SD) }\end{array}$ & $\begin{array}{c}\geqslant 10 \mathrm{mg} / \mathrm{m}^{3} \\
\text { Mean }(S D)\end{array}$ & P value \\
\hline Right eye: & & & \\
Before shift & $0.509(0.023)$ & $0.529(0.036)$ & 0.2077 \\
After shift & $0.508(0.023)$ & $0.528(0.031)$ & 0.1529 \\
P value & 0.9223 & 0.9854 & \\
Left eye: & & & 0.0260 \\
Before shift & $0.514(0.017)$ & $0.544(0.031)$ & $0.538(0.028)$ \\
After shift & $0.512(0.023)$ & 0.0678 \\
P value & 0.7857 & 0.7633 & \\
\hline
\end{tabular}

composition ( $\%$ black: $55 \%, 61 \%$, and $61 \%$, $P=0.9054)$, and sex ( $\%$ men: $100 \%, 87 \%$, and $96 \%, P=0 \cdot 1846$ ).

Table 1 shows vision symptoms that have previously been reported to be associated with exposure to triethylamine. At the initial examination, the currently exposed group had significantly higher percentages of workers who reported blurry vision, halos, blue vision, and trouble with driving.

The follow up examination assessed the same vision symptoms actually on that day (table 1). For both days of the follow up examinations, the currently exposed group had significantly higher numbers of people with blurry vision (except after the shift on day 1), halos around lights, and blue vision. No workers experienced trouble with driving due to vision problems after the shift on the actual days of the follow up examinations.

As well as the vision symptoms shown in table 1, the three groups were assessed for pain, redness and burning of the eyes, and sensitivity to light; there were no significant differences between the groups. Only two workers in the study ever wore contact lenses; one had not worn them for a year and the other had not worn them for at least 18 hours before the first examination and had discontinued wearing them when the second examination was conducted. There was no difference among the three groups in the frequency of use of eye drops or ever having had an eye injury. No one in any of the three groups was taking eye medications or had a family history of eye disease. For specific types of eye injuries, the previously and never exposed groups had a significantly greater number of workers who had had a foreign object removed or a scratch of the eye.

A comparison of the mean measurements for visual acuity without correction, with correction, and pinhole showed no differences among the three exposure groups. Stromal opacities (scars) and guttata (corneal endothelial deposits) were found in members of each exposure group; no one had corneal oedema. There were no significant differences in either the right or left eyes between the currently, previously, or never exposed groups for either abnormal conjunctiva (right eye: $5 \%$, $4 \%$, and $4 \%, P=0.9932$; left eye: $5 \%, 4 \%$, $0 \%, P=0.5716$ ) or corneas (right eye: $25 \%$, $52 \%, 35 \%, P=0 \cdot 1737$; left eye: $35 \%, 48 \%$, $30 \%, P=0.4540$ ). Except for one previously exposed worker with shallow depth, the study participants had normal anterior chambers and lenses.

Table 2 shows air monitoring results for triethylamine for each person in the currently exposed group, along with their reported symptoms, triethylamine leaks, or excessive exposures, and changes in corneal thickness. Triethylamine exposures measured during the two days ranged from $<0.33 \mathrm{mg} / \mathrm{m}^{3}$ to 20.3 $\mathrm{mg} / \mathrm{m} .^{3}$ Changes in corneal thickness by comparison of values before to after the shift both increased and decreased and were not necessarily in the same direction for both eyes. Increases in corneal thickness ranged from 
$0.001 \mathrm{~mm}$ to $0.011 \mathrm{~mm}$; decreases ranged from $0.001 \mathrm{~mm}$ to $0.020 \mathrm{~mm}$.

No significant differences were found in the mean central corneal thickness for each exposure group by shift and day (table 3 ). The mean central corneal thicknesses ranged from $0.511 \mathrm{~mm}$ to $0.525 \mathrm{~mm}$. For the currently exposed group, three of the four mean before and after shift corneal thickness measurements in the right and left eyes showed decreases in corneal thickness by the end of the shift on both days. When changes in corneal thickness for both right and left eye were combined, both days showed a decrease in corneal thickness of $0.003 \mathrm{~mm}$; the decrease on the first day but not the second day was significant $(P=0.0470$ and $P=$ 0.2271 respectively).

Table 4 shows that all but two of the mean central corneal thickness measurements of the currently exposed group were decreased on the second day at the end of the working week compared with the first day at the beginning of the work week; two of the decreases were significant.

To determine if increases in corneal thickness were associated only with symptomatic workers, the exposure groups were stratified according to reports of vision symptoms. None of these differences were significant (table 5).

Table 6 shows that people exposed to $\geqslant 10$ $\mathrm{mg} / \mathrm{m}^{3}$ of triethylamine were three times more likely to have one or more symptoms associated with triethylamine exposure than those with $<10 \mathrm{mg} / \mathrm{m}^{3}$ exposure; this finding was not significant.

Comparisons of corneal thickness between workers with exposure to $<10 \mathrm{mg} / \mathrm{m}^{3}$ and $\geqslant 10 \mathrm{mg} / \mathrm{m}^{3}$ were made (table 7). Corneal thickness measurements decreased during a shift in both exposure categories. Between exposure categories, corneal thickness measurements were larger in people exposed to $\geqslant 10 \mathrm{mg} / \mathrm{m}^{3}$ triethylamine. This difference was significant in the left eye for the measurements before the shift.

\section{Discussion}

Central corneal thickness under normal conditions has been reported by several researchers. Ranges reported are from 0.507 $(0.028)$ to $0.565(0.035) \mathrm{mm}^{.910} \mathrm{We}$ found corneal thicknesses from 0.470 to $0.567 \mathrm{~mm}$ among workers currently exposed to triethylamine, 0.460 to $0.583 \mathrm{~mm}$ among those previously exposed, and 0.456 to $0.620 \mathrm{~mm}$ among those never exposed (table 3 ). These results are close to the reported normal range of central corneal thickness.

At the first eye examination, the two ophthalmologists, one a corneal specialist, found no corneal oedema with a slit lamp. The significant differences in reports of vision symptoms between the three groups were for the symptoms of blurry vision, halos around lights, blue vision, and trouble with driving (table 1), all of which have been associated with exposure to triethylamine. ${ }^{1-7}$ Other symptoms such as eye irritation, eye redness, sensitivity to light, and eye pain were similar among the three groups.

At the follow up eye examinations the exposed group again reported the symptoms of blurry vision, halos, and blue vision more often than the previously and never exposed groups (table 1). In the examinations after a shift the subjects were asked to report symptoms that had occurred during that shift. No differences in corneal thickness between the currently and previously or never exposed groups or differences between before and after the shift measurements suggested corneal oedema as the mechanism for these symptoms (tables 2, 3, and 4).

Vision symptoms after exposure to tertiary amines have been associated with increases in corneal thickness that ranged from 0.03 to $0.10 \mathrm{~mm}$. Stahlbom and colleagues reported slight oedema (approximately $0.03 \mathrm{~mm}$ increase) in two of four subjects exposed to as little as $10 \mathrm{mg} / \mathrm{m}^{3}$ of dimethylethylamine. ${ }^{6}$ Akesson and colleagues exposed two subjects to different concentrations and durations of triethylamine in an exposure chamber. ${ }^{3}$ They found symptoms of hazy and halo vision after eight hours of exposure at concentrations as low as $18 \mathrm{mg} / \mathrm{m}^{3}$ of triethylamine, along with an increase in corneal thickness of $0.03 \mathrm{~mm}$. At an exposure of $10 \mathrm{mg} / \mathrm{m}^{3}$ of triethylamine for eight hours, the two subjects experienced no effects. Akesson and colleagues concluded that an exposure of $18 \mathrm{mg} / \mathrm{m}^{3}$ for eight hours can cause corneal oedema. The triethylamine exposures we measured ranged from $<0.33$ $\mathrm{mg} / \mathrm{m}^{3}$ to $20.3 \mathrm{mg} / \mathrm{m}^{3}$. The changes in corneal thickness we measured ranged from a decrease of $0.020 \mathrm{~mm}$ to an increase of 0.011 $\mathrm{mm}$ within a shift. The maximum change in corneal thickness that we noted was less than the minimum change of corneal thickness associated with symptoms in the experimental settings reported by Akesson and Stahlbom. ${ }^{36}$

We compared mean corneal thickness of currently exposed workers with one or more eye symptoms to those with no symptoms. There were no significant changes over the shift that showed an increase in corneal thickness in either symptom level group. Workers with one or more symptoms had thicker corneas than the previously and never exposed groups. Differences in corneal thickness were as great as $0.032 \mathrm{~mm}$, which is the minimum difference associated with symptoms in experimental settings. None of these differences were significant (table 5).

We also examined whether the workers who had exposures to triethylamine $\geqslant 10$ $\mathrm{mg} / \mathrm{m}^{3}$, were more symptomatic and had increased corneal thickness. Although not significant, there was a threefold increase in eye symptoms among the workers exposed to $\geqslant 10 \mathrm{mg} / \mathrm{m}^{3}$ of triethylamine (table 6). We found, however, no increase in corneal thickness before and after the shift in either eye in the workers exposed to $\geqslant 10 \mathrm{mg} / \mathrm{m}^{3}$ (table 7 ). There was a significant difference of $0.03 \mathrm{~mm}$ in the mean corneal thickness of the left eye on the measurements before the shift between 
people exposed to $\geqslant 10 \mathrm{mg} / \mathrm{m}^{3} v$ those exposed to $<10 \mathrm{mg} / \mathrm{m}^{3}$ (table 7). After the shift the difference was similar $(0.026 \mathrm{~mm})$ but not significant. Although the differences in corneal thickness and symptoms between workers exposed to $\geqslant 10 \mathrm{mg} / \mathrm{m}^{3}$ and $<10$ $\mathrm{mg} / \mathrm{m}^{3}$ are consistent, one would also have expected to see a change from before to after the shift in the $\geqslant 10 \mathrm{mg} / \mathrm{m}^{3}$ group if an increase in corneal thickness is an explanation of the workers' symptoms.

One other researcher has reported symptoms at similar levels of exposure as our study group. Akesson et al examined 19 workers exposed to triethylamine in a polyurethane foam production plant. ${ }^{4}$ Central corneal thickness measured from $0.53 \mathrm{~mm}$ to 0.61 $\mathrm{mm}$, and workers reported symptoms of foggy, blue, and halo vision, which were usually preceded by eye irritation. Exposures ranged from 4 to $28 \mathrm{mg} / \mathrm{m}^{3}$ in the areas where workers reported visual disturbances. Exposures for two hours were not associated with any vision disturbances. The researchers did not find any corneal oedema but measurements were not taken immediately after exposure. The authors hypothesised that the reason symptoms occurred at such low exposures was that there may have been peak exposures of high concentrations of triethylamine during the course of the shift. ${ }^{4}$

In contrast, we performed our corneal thickness measurements immediately after the shift and found no changes in corneal thickness over the shift. Alternative explanations for our findings are that symptoms are related to another exposure, that the mechanism for triethylamine or another exposure causing symptoms is not through corneal oedema, that there is a small increase in corneal thickness over time that is not reflected in changes in an eight hour shift, or that corneal oedema is transient.

None of the other exposures in the cold box area have been previously associated with the vision symptoms of haziness, blue colour, and halos. Further, isolated exposure to triethylamine in experimental settings has caused these vision symptoms. Amines have been noted to have other effects on the eye, including mydriasis and cycloplegia. ${ }^{1}$ Neither of these abnormalities were noted on physical examination although no measurements were performed to measure changes in pupil size or reaction. Finally, although there were differences in corneal thickness between currently exposed and previously or never exposed people, there was no difference between corneal measurements before the shift at the beginning of the week and measurements after the shift at the end of the week. No chronic corneal changes were noted after exposure to triethylamine. All the small differences in corneal thickness found are within the clinically normal range.

None of the alternative hypotheses adequately explain the presence of symptoms in the exposed workers or the increased symptoms in the group exposed to $\geqslant 10 \mathrm{mg} / \mathrm{m}^{3}$ triethylamine. Limitations in the study that might account for our inability to find an association between vision symptoms and measurements of corneal thickness include inaccurate measurement of corneal thickness, inaccurate collection of information on eye symptoms, or inaccurate measurement of triethylamine exposures. We do not think that these potential limitations explain our results. All measurements of corneal thickness were performed with the same instrument by the same technician who was unaware of the exposures of the workers tested. It is unlikely that workers misunderstood the questionnaire as not all eye symptoms but only symptoms associated with triethylamine were increased among the currently exposed group. Similar sampling results were obtained with exposures to charcoal and silica gel that were taken during overlapping times; we therefore think that the exposure measurements were accurate.

Small numbers limited our ability to find significant differences, but even in the absence of a significant difference the direction of the findings, although supporting an association between symptoms and exposure, did not support an association between corneal thickness and exposure.

\section{Conclusion}

In summary, the air monitoring results showed exposures to triethylamine that ranged from $<0.33 \mathrm{mg} / \mathrm{m}^{3}$ to $20.3 \mathrm{mg} / \mathrm{m}^{3}$. Despite these relatively low air concentrations and the absence of corneal oedema, workers reported vision symptoms associated with exposure to triethylamine. It is possible that the exposures were low enough that oedema did not occur, although corneal oedema has been reported with an exposure as low as 18 $\mathrm{mg} / \mathrm{m}^{3}$ for eight hours in one study. ${ }^{3}$ Another possibility is that variability between people or unmeasured peak excursions caused transient changes in corneal thickness that were not present on measurements after the shift. Amines have been noted to cause mydriasis and cycloplegia and this effect on the ciliary muscle instead of corneal oedema warrants further study as this may be the mechanism for the symptoms found at these relatively low concentrations. ${ }^{1}$ Further studies need to be performed to attempt to correlate objective signs of decrements in visual acuity with the reported vision symptoms. One relatively new test that may prove to be useful to this end is contrast sensitivity, which tests a person's ability to discriminate between levels of contrast. The current Occupational Safety and Health Administration standard for an eight hour exposure to triethylamine is $100 \mathrm{mg} / \mathrm{m}^{3}$. At the time of our study the ACGIH recommend a concentration of $40 \mathrm{mg} / \mathrm{m}^{3}$. Although we are unable to explain the mechanism, we found that vision symptoms occurred at concentrations lower than both the current Occupational Safety and Health Administration standard and the recommended ACGIH concentration at the time of our study. Although no chronic eye problems were found, the potential for an acute injury 
at work or while driving home because of difficulty in seeing indicates a need to minimise exposure to triethylamine below those standards currently considered acceptable. Given that $59 \%$ of the workers experienced symptoms at or below the recommended ACGIH concentration at the time of our study, our data would support the new lower recommended ACGIH concentration of $4 \cdot 1 \mathrm{mg} / \mathrm{m}^{3}$.

The project was funded by joint funds from the UAW and Chrysler National Joint Committee on Health and Safety. The results represent the conclusions and opinions of the authors. Its publication does not necessarily imply endorsement by the International Union UAW, or Chrysler Corporation.

1 Albrecht W, Stephenson R. Health hazards of tertiar amine catalysts. Scand $\mathcal{f}$ Work Environ Health 1988;14: 209-19.
2 Brieger H, Hodes WA. Toxic effects of exposure to vapors of aliphatic amines. Archives of Industrial Hygiene 1951 3:287-91.

3 Akesson B, Floren I, Skerfving S. Visual disturbances after experimental human exposure to triethylamine. $\mathrm{Br} f$ Ind Med 1985;42:848-50.

4 Akesson B, Bengtsson M, Floren I. Visual disturbances after industrial Environ Health 1986;57:297-302.

5 Mellerio J, Weale RA. Miscellanea: hazy vision in amine Mellerio J, Weale RA. Miscellanea: hazy vision
plant operatives. Br f Ind Med 1966;23:153-8.

6 Stahlbom B, Lundh T, Floren I, Akesson B. Visual disturbances in man as a result of experimental and occupational exposure to dimethylethylamine. $\mathrm{Br} \mathrm{F}$ Ind $\mathrm{Med}$ 1991;48:26-9.

7 US Department of Health and Human Services, PHS, CDC, NIOSH. NIOSH alert: report for assistance in preventing vision disturbances and acute physical distress due to dimethylethylamine (DMEA) exposure. Washington: NIOSH, 1987.

8 Warren Jr D, Selchan D. An industrial hygiene appraisal of triethylamine and dimethylethylamine exposure limits in triethy $630-4$. $630-4$

9 Hansen F. A clinical study of the normal human central corneal thickness. ACTA Ophthalmol 1971;49:82-9.

10 Kremer F, Walton P, Gensheimer G. Determination of corneal thickness using ultrasonic pachometry. Ann Ophthalmol 1985;17:506-7.

\section{Rejected manuscripts}

From February 1994, authors whose submitted articles are rejected will be advised of the decision and one copy of the article, together with any reviewers' comments, will be returned to them. The fournal will destroy remaining copies of the article but correspondence and reviewers' comments will be kept. 